\title{
Изучение увологических и агробиологических показателей сорта винограда Кокур белый на различных подвоях для проведения клоновой селекции
}

Наталия Леонидовна Студенникова, канд. с.-х. наук, вед. науч. сотр. лаборатории генеративной и клоновой селекции, studennikova63@mail.ru;

Зинаида Викторовна Котоловець, канд. с.-х. наук, науч. сотр. лаборатории генеративной и клоновой селекции, zinaida kv@mail.ru

Федеральное государственное бюджетное учреждение науки «Всероссийский национальный научно-исследовательский институт виноградарства и виноделия «Магарач» РАН», Россия, Республика Крым, г. Ялта, ул. Кирова, 31, 298600

\begin{abstract}
Представлены результаты работы по изучению влияния филлоксероустойчивых подвоев Берландиери × Рипариа Кобер 5ББ и Берландиери × Рипариа Телеки 4Б (CO4) на агробиологические и увологические показатели крымского технического белоягодного аборигенного сорта винограда Кокур белый в условиях Алуштинской долины (филиал «Алушта» ФГУП «ПАО «Массандра»). Для проведения исследований были выбраны: участок № 361, площадью 4,49 га, на котором произрастают кусты винограда Кокур белый, привитые на подвое Берландиери × Рипариа Кобер 5 ББ (2010 год посадки, схема 3 м ×1,25 м) и участок № 391 , площадью 3,06 га, на котором возделываются растения сорта Кокур белый, привитые на подвое Берландиери × Рипариа Телеки 4Б (СО4) - 2011 год посадки, схема 3 м × 1 м). На обоих участках система ведения кустов - вертикальная трехпроволочная шпалера, формировка АЗОС-1, высота штамба - 1,3 м. Показана целесообразность проведения работ по улучшению сорта Кокур белый методом клоновой селекции на сортоподвойной комбинации Кокур белый подвой Кобер 5 ББ: у растений отмечен высокий уровень коэффициента плодоношения $(0,92)$, довольно крупные грозди (365 г), урожай с куста в среднем составил 4,74 кг/ куст, очень высокая продуктивность побега по сырой массе грозди - 336,6 г/побег, большой процент выхода мякоти и сока - 91,3\%. Оценка имеющихся сортоподвойных комбинаций в производственных условиях позволила провести индивидуальный отбор генотипически ценных в биолого-хозяйственном отношении форм растений.
\end{abstract}

Ключевые слова: сорт; подвой; клоновая селекция; увология; сортоподвойные комбинации.

K окур белый - крымский технический сорт винограда народной селекции, среднепозанего периода созревания. По морфологическим признакам и биомогическим свойствам относится к эколого-географической группе сортов бассейна

\footnotetext{
Как цитировать эту статью:

Студенникова Н.Л., Котоловець З.В. Изучение увологических и агробиологических показателей сорта винограда Кокур белый на различных подвоях для проведения клоновой селекции // "Магарач». Виноградарство и виноделие, 2019; 21(2). С. 105-108.

DOI 10.35547/IM.2019.21.2.005

How to cite this article:

Studennikova N.L., Kotolovets Z.V. The study of uvological and agrobiological indicators of 'Kokur White' grapevine cultivar on various rootstocks for the purpose of clonal breeding. Magarach. Viticulture and Winemaking, 2019; 21(2); pp. 105-108. DOI 10.35547/IM.2019.21.2.005

удК 634.85:631.524.8/.527.6:631.541.11

Поступила 29.10.2018

Принята к публикации 11.02.2019

(C) Авторы, 2019
}

O R I G I N A L A R T I C L E

\section{The study of uvological and agrobiological indicators of 'Kokur White' grapevine cultivar on various rootstocks for the purpose of clonal breeding}

Nataliya Leonidovna Studennikova, Zinaida Viktorovna Kotolovet

Federal State Budgetary Scientific Institution All-Russian National Research Institute of Viticulture and Winemaking "Magarach" of RAS, 31 Kirova Str., 298600 Yalta, Republic of Crimea, Russian Federation

The paper reports on the findings of a study on the influence of phylloxeraresistant rootstocks 'Berlandieri' ×'Riparia Kober 5BB' and 'Berlandieri'×'Riparia Teleki 4B (CO4)' on the agro-biological and uvological indicators of Crimean aboriginal grapevine variety used in winemaking 'Kokur Beliy in the conditions of Alushta valley (branch of Alushta FGUP PAO Massandra). The following were selected for research: plot № 361 with an area of 4.49 hectares with bushes of 'Kokur Beliy' grafted on rootstock of 'Berlandieri' × Riparia Kobera 5 BB' (planting year - 2010, planting scheme $3 \mathrm{~m} \times 1.25 \mathrm{~m}$ ) and plot № 391 covering 3.06 hectares with 'Kokur Beliy' vines grafted on 'Berlandieri' × 'Riparia Teleki $4 \mathrm{~B}$ (CO4)' rootstock - planting year -2011 , planting scheme $3 \mathrm{~m} \times 1 \mathrm{~m}$ ). On both plots, the training system used was vertical three-wire trellis, vines shaped as AZOS-1, the trunk height $1.3 \mathrm{~m}$. The paper demonstrates the relevance of the work on improvement of 'Kokur Beliy' cultivar with the help of clonal breeding on rootstock cultivar combination 'Kokur Beliy' rootstock 'Kober 5 BB': the plants demonstrated high relative productivity (0.92), quite large bunches (365 $\mathrm{g})$, yield per bush made on average $4.74 \mathrm{~kg} /$ bush, very high shoot productivity as per raw bunch weight $336.6 \mathrm{~g} /$ shoot, a large percentage of pulp and juice output - $91.3 \%$. Assessment of the cultivar-rootstock combinations under production conditions allowed making individual selection of genotypically valuable, from the biological and economic points of view, plants..

Key words: cultivar; rootstock; clone selection; uvology; cultivarrootstock combinations.

Черного моря. Широко распространен в Крыму и в Ростовской области. Используется Аця приготовления соков, шампанских виноматериалов, столовых, крепких и десертных вин [1].

Алительность и широкий ареац культивирования сорта способствовали появцению отрицательных и положительных мутаций. В процессе работы с сортом отмечено появление функционально мужских и женских цветков, собранных на укороченной оси и впоследствии образующих мелкие и нетипичные, очень рыхлые грозди с горошащимися ягодами [2-4]. Эти изменения передавались вегетативному потомству и были одной из причин появ ения бесп одных кустов с мощным габитусом. Проявмение вегетативной изменчивости растений, ведущей к их ухуАшению, возможно убрать только целенаправленным отбором. Кроме того, в обеспечении высокой и стабимьной урожайности сорта важная роль принадлежит подвою, который, снижая или повышая аАаптационные возможности сортоподвойных комбинаций к условиям среды, определяет урожайность и качество урожая [5-11]. Поэтому подбор пмодоносящих насаждений (участков первичного отбора) и оценка имеющихся сортопоА- 
Таблица 1. Увологические показатели гроздей и ягод сорта Кокур белый на изучаемых подвоях, 2016-2018 гг. Table 1. Uvological characteristics of bunches and berries of 'Kokur Beliy' cultivar on the studied rootstocks, 2016-2018.

\begin{tabular}{|c|c|c|c|c|c|c|c|c|c|c|c|c|c|c|}
\hline \multirow{2}{*}{$\begin{array}{l}\text { Сортоподвой } \\
\text { ные комбин- } \\
\text { ции }\end{array}$} & \multirow{2}{*}{$\begin{array}{l}\text { Масса } \\
\text { гроз- } \\
\text { АИ, Г }\end{array}$} & \multirow{2}{*}{$\begin{array}{l}\text { Мacca } \\
\text { греб- } \\
\text { ня, г }\end{array}$} & \multirow{2}{*}{$\begin{array}{l}\text { Коли- } \\
\text { чество } \\
\text { ягоА В } \\
\text { грозАи, } \\
\text { шт. }\end{array}$} & \multirow{2}{*}{$\begin{array}{l}\text { Коли- } \\
\text { чество } \\
\text { семян в в } \\
\text { грозди, } \\
\text { шт. }\end{array}$} & \multirow{2}{*}{$\begin{array}{l}\text { Macca } \\
100 \\
\text { ягоА, Г }\end{array}$} & \multirow{2}{*}{$\begin{array}{l}\text { Масса } \\
\text { кожи- } \\
\text { цы } 100 \\
\text { ягоА, Г }\end{array}$} & \multirow{2}{*}{$\begin{array}{l}\text { Масса } \\
\text { семян } \\
100 \\
\text { ягоА, Г }\end{array}$} & \multirow{2}{*}{$\begin{array}{l}\text { Масса } \\
\text { мякоти } \\
\text { и сока } \\
100 \\
\text { ягоА, Г }\end{array}$} & \multirow{2}{*}{$\begin{array}{l}\text { Macca } \\
100 \text { се- } \\
\text { мян, г }\end{array}$} & \multicolumn{5}{|c|}{ Процент к грозАи } \\
\hline & & & & & & & & & & гребня & ягОА & семян & кожицы & $\begin{array}{l}\text { мякоти } \\
\text { и сока }\end{array}$ \\
\hline \multirow{3}{*}{$\begin{array}{l}\text { Кокур белый } \\
\times \text { Кобер 5ББ }\end{array}$} & 360 & 9,0 & 143 & 158 & 263 & 9,6 & 4,8 & 248,6 & 3,9 & 2,5 & 97,5 & 2,16 & 3.92 & 91,42 \\
\hline & 387 & 11,0 & 153 & 176 & 247 & 9,0 & 5,0 & 233,0 & 3,9 & 2,85 & 97,15 & 2,34 & 3,67 & 91,14 \\
\hline & 348 & 8,6 & 146 & 162 & 253 & 9,3 & 4,5 & 251,3 & 3,7 & 2,47 & 97,53 & 2,15 & 4,0 & 91,38 \\
\hline среанее & 365 & 9,53 & 147,3 & 165,3 & 254,3 & 9,3 & 4,77 & 244,3 & 3,83 & 2,6 & 97,39 & 2,22 & 3,86 & 91,31 \\
\hline ошибка & 11,5 & 0,76 & 2,96 & 5,46 & 4,66 & 0,17 & 0,15 & 5,71 & 0,41 & 0,12 & 0,12 & 0,06 & 0,09 & 0,09 \\
\hline $\mathrm{HCP}_{05}$ & 20,52 & 1,36 & 5,27 & 9,71 & 8,30 & 0,31 & 0,26 & 10,14 & 0,30 & 0,22 & 0,22 & 0,11 & 0,17 & 0,15 \\
\hline \multirow{3}{*}{$\begin{array}{l}\text { Кокур белый } \\
\text { × СО4 }\end{array}$} & 238 & 7,0 & 171 & 210 & 136 & 7,8 & 4,0 & 124,2 & 3,0 & 2,95 & 97,05 & 3,64 & 5,78 & 87,63 \\
\hline & 298 & 9,0 & 165 & 188 & 172 & 8,8 & 4,5 & 159,3 & 3,4 & 3,02 & 96,98 & 2,93 & 5,03 & 89,02 \\
\hline & 310 & 9,0 & 157 & 196 & 168 & 8,0 & 4,5 & 152,0 & 3,4 & 2,9 & 97,1 & 2,93 & 4,17 & 90,0 \\
\hline среднее & 282 & 8,33 & 164,3 & 198 & 158,7 & 8,2 & 4,33 & 145,17 & 3,27 & 2,96 & 97,04 & 3,17 & 4,99 & 88,88 \\
\hline ошибка & 22,29 & 0,67 & 4,06 & 6,44 & 11,41 & 0,31 & 0,17 & 6,18 & 0,13 & 0,03 & 0,03 & 0,24 & 0,44 & 0,69 \\
\hline $\mathrm{HCP}_{05}$ & 33,6 & 1,18 & 7,2 & 11,43 & 20,2 & 0,53 & 0,3 & 10,9 & 0,24 & 0,06 & 0,06 & 0,42 & 0,78 & 1,22 \\
\hline
\end{tabular}

войных комбинаций в производственных условиях позволяют проводить индивиАуацьный отбор генотипически ценных в биолого-хозяйственном отношении форм растений.

Аостаточно много исследований посвящено вопросу изучения сорта Кокур бемый [12, 13]. Работа по его укучшению была начата в 2016 году на землях фикиала «Алушта» ФГУП «ПАО «Массандра». В изучение быми взяты: участок №361, пмощадью 4,49 га, на котором произрастают кусты винограда Кокур белый, привитые на подвое Бермандиери $\times$ Рипариа Кобер 5 ББ (2010 год посадки, схема $3 \times 1,25$ м) и участок № 391, площадью 3,06 га, на котором воздемываются растения сорта Кокур бемый, привитые на поАвое Берландиери $\times$ Рипариа Темеки 4Б (СО4) - 2011 год посадки, схема 3 м $\times 1$ м) на обоих участках система ведения кустов - вертикацьная трехпроволочная шпалера, формировка АЗОС-1, высота штамба 1,3 м.

Цель исследований - оценка сортоподвойных комбинаций сорта винограда Кокур белый по агробиологическим показателям и увологическим особенностям грозАей и ягоА ААя послеАУющего провеАения клоновой селекции в условиях Алуштинской долины.

Работа проводикась по общепринятым методикам [14-16].

Увологические показатели гроздей и ягоА сортоподвойных комбинаций по трем повторностям за 2016-2018 годы преАставлены в табл.1.

Анализируя основные величины механического состава - процент гребней и ягоА в составе грозАи, необходимо отметить, что в среднем за годы исследований грозди обеих комбинаций содержали более $97 \%$ ягоА От всей массы грозди.

Средняя масса грозди сорта Кокур белый (подвой Кобер 5 ББ) в 1,3 раза превосходила этот показатель в комбинации Кокур белый (подвой СО4), Аостигая в среАнем $365 \pm 11,5$ г.
Масса 100 ягод сортоподвойной комбинации Кокур белый на подвое Кобер 5 ББ в среднем составила $254,3 \pm 4,66$ г, превышая это значение на 95 г в сортоподвойной комбинации Кокур белый на подвое СО4. Аля технических сортов очень важной характеристикой явАяется процент сока и мякоти в общей массе грозди. Аанный показатель в сортоподвойной комбинации Кокур белый, привитый на подвое СО4, достигац $88,88 \pm 0,69 \%$, что на 2,43\% меньше по сравнению с растениями сортоподвойной комбинацией Кокур белый (подвой Кобер 5 ББ).

В табл. 2 приведены агробиологические показатеми сорта Кокур белый на изучаемых подвоях.

В результате анализа агробиологических показателей установлено, что средняя нагрузка куста глазками в популяции сорта Кокур белый (подвой Кобер 5 ББ) составика 23,3 $\pm 0,88$ шт., развившимися побегами - 20,7 $\pm 1,45$ шт., что в 1,3 раза превышает эти показатели в сортоподвойной комбинации Кокур белый (подвой СО4). Средняя величина показателя «коэффициент плодоношения» $\left(K_{1}\right)$ в популяции Кокур

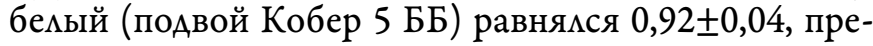
вышая ее в 1,08 раза по сравнению с популяцией сорта Кокур белый (подвой СО4) $(0,85 \pm 0,08)$. Среднее значение признака «количество гроздей на куст» по обеим популяциям находимось на оАном уровне: $12 \pm$ $1,53-13 \pm 0,41$ шт.

В популяции сорта Кокур белый (подвой Кобер 5 ББ) величина показателя «среАняя масса грозди» достигала в среднем $365 \pm 11,5$ г, превосходя в 1,3 раза это значение в популяции Кокур белый на поАвое CO4 $(228,2 \pm 22,29$ г). По признаку «урожай с куста» растения в сортоподвойной комбинации Кокур белый, привитые на подвое Кобер 5 ББ $(4,74 \pm 0,08$ кг/куст) превосходили в 1,4 раза представителей попумяции Кокур белый, привитых на подвое СО4 (3,36 $\pm 0,43$ кг/куст). 
Таблица 2. Агробиологические показатели сорта Кокур белый на изучаемых подвоях, 2016 - 2018 гг.

Table 2. Agrobiological performance of 'Kokur Beliy' cultivar on the studied rootstocks, 2016-2018

\begin{tabular}{|c|c|c|c|c|c|c|c|c|c|}
\hline \multirow{2}{*}{$\begin{array}{l}\text { Показа- } \\
\text { тель } \\
\text { Годы }\end{array}$} & \multicolumn{3}{|c|}{ Количество } & \multirow{2}{*}{$\begin{array}{l}\text { Коэффици- } \\
\text { ент плодоно- } \\
\text { шения К }\end{array}$} & \multirow{2}{*}{$\begin{array}{l}\text { Количе- } \\
\text { ство гроз- } \\
\text { Аей, шт. }\end{array}$} & \multirow{2}{*}{$\begin{array}{l}\text { СреА- } \\
\text { няя } \\
\text { масса } \\
\text { грозАи, Г }\end{array}$} & \multirow{2}{*}{$\begin{array}{l}\text { Урожай- } \\
\text { ность, кг/ } \\
\text { куст }\end{array}$} & \multirow{2}{*}{$\begin{array}{l}\text { Продуктив- } \\
\text { ность побега, } \\
\text { г/побег }\end{array}$} & \multirow{2}{*}{$\begin{array}{l}\text { Массовая } \\
\text { концентрация } \\
\text { сахаров, г/Ам }\end{array}$} \\
\hline & $\begin{array}{l}\text { глазков, } \\
\text { шт. }\end{array}$ & $\begin{array}{l}\text { развившихся } \\
\text { побегов, шт. }\end{array}$ & $\begin{array}{l}\text { соцветий, } \\
\text { шт. }\end{array}$ & & & & & & \\
\hline
\end{tabular}

Кокур белый, привитый на подвое Кобер 5ББ

\begin{tabular}{|c|c|c|c|c|c|c|c|c|c|}
\hline 2016 & 22 & 18 & 18 & 1,0 & 13 & 360 & 4,68 & 360,0 & 215,0 \\
\hline 2017 & 25 & 23 & 20 & 0,87 & 12 & 387 & 4,64 & 336,7 & 220,0 \\
\hline 2018 & 23 & 21 & 19 & 0,90 & 14 & 348 & 4,9 & 313,2 & 230,0 \\
\hline среднее & 23,3 & 20,7 & 19 & 0,92 & 13 & 365 & 4,74 & 336,6 & 221,7 \\
\hline ошибка & 0,88 & 1,45 & 0,56 & 0,04 & 0,41 & 11,5 & 0,08 & 13,5 & 4,39 \\
\hline $\mathrm{HCP}_{05}$ & 1,56 & 2,59 & 1,03 & 0,07 & 0,73 & 20,52 & 0,14 & 24,05 & 7,8 \\
\hline
\end{tabular}

Кокур бемый, привитый на подвое $\mathrm{CO} 4$

\begin{tabular}{|c|c|c|c|c|c|c|c|c|c|}
\hline 2016 & 18 & 16 & 13 & 0,82 & 13 & 238 & 3,09 & 195,2 & 220,0 \\
\hline 2017 & 18 & 16 & 16 & 1,0 & 14 & 298 & 4,2 & 298 & 230,0 \\
\hline 2018 & 19 & 15 & 11 & 0,73 & 9 & 310 & 2,79 & 226,3 & 235,0 \\
\hline среднее & 18,3 & 15,7 & 13,3 & 0,85 & 12 & 282,2 & 3,36 & 239,8 & 228,3 \\
\hline ошибка & 0,33 & 0,33 & 1,45 & 0,08 & 1,53 & 22,29 & 0,43 & 30,5 & 4,4 \\
\hline $\mathrm{HCP}_{05}$ & 0,59 & 0,59 & 2,59 & 0,14 & 2,72 & 39,6 & 0,76 & 54,16 & 7,8 \\
\hline
\end{tabular}

В качестве интегрирующей характеристики проАуктивности кустов целесообразно использовать «индекс продуктивности сорта» [16]. Уровень показателя «продуктивность г/побег по сырой массе грозди» у преАставителей популяции Кокур бемый (подвой Кобер 5 ББ) составмя $336,6 \pm 13,5$ г/побег и характеризовался как «очень высокий», а у растений в популяции Кокур белый (подвой СО4) - 239,8 $\pm 30,5$ г/побег и характеризовацся как «высокий». Следует отметить, что за годы исследования ягоды растений сортоподвойной комбинации Кокур белый на подвое CO4 накапливали более высокое количество сахаров, в среднем 228,3 \pm 4,4 г/Ам³ ями популяции Кокур белый, привитыми на подвое Кобер 5 ББ $\left(221,7 \pm 4,39\right.$ г/ $\left.\mathrm{AM}^{3}\right)$.

Таким образом, сорт Кокур белый несомненно нужАается в укучшении и постоянном сортоподАержании. Исследование увологических и агробиологических показателей сорта Кокур белый на размичных подвоях показаАо, что у растений в сорто-поАвойной комбинации Кокур белый (подвой Кобер 5ББ) отмечен высокий уровень коэффициента пмодоношения $(0,92)$, Аовольно крупные грозди (365 г), урожай с куста в среднем - 4,74 кг/куст, очень высокая продуктивность побега по сырой массе грозди - 336,6 г/побег, большой процент выхода мякоти и сока - 91,3\%. Уровень сахаронакопмения в ягодах обеих популяций обеспечивает получение виноматериалов Аһя игристых вин, а также сырья Аля производства столовых вин [17].

На основании вышеизможенного целесообразно проводить работы по улучшению сорта Кокур белый методом кмоновой селекции на производственном участке, где возделываются растения винограда, при- витые на подвое Берландиери $\times$ Рипариа Кобера 5 ББ. Источники финансирования

Работа выполнена в рамках государственного заАания № 0833-2019-0006.

\section{Financing source}

The study was conducted within the framework of the State assignment № 0833-2019-0006.

\section{Конфликт интересов}

Не заявлен.

\section{Conflict of interests}

Not declared.

\section{Список литературы / References}

1. Энциклопедия виноградарства. - Кишинев: Гл. Ред. Молд.Сов. Энц. 1986. - T. II. - C. 52

Jenciklopedija vinogradarstva [Encyclopedia of viticulture]. Kishenev: Ch. Ed. Mold.Sov. Ents., 1986. V. II. p. 52. (in Russian)

2. Кокур белый / Ампелография СССР . - М.: Пищепромиздат, 1954. - С. 274-279.

Kokur belyj / Ampelografija SSSR [Kokur white / USSR ampelography]. -: Pishepromizdat. - 1954. - p. 274-279. (in Russian)

3. Коробец, П.В. Ускоренные методы массовой селекции винограда / П.В. Коробец. - Симферополь: Крымиздат, 1963. - 62 с.

Korobec P.V. Uskorennye metody massovoj selekcii vinograda [Accelerated methods for routine grapevine breeding] Simferopol: Krymizdat. 1963. 62 p. (in Russian)

4. Студенникова, Н.Л. Клон винограда сорта Кокур белый с осыпанием цветков и частичным горошением ягод / Н.Л. Студенникова, 3.В. Котоловець // «Магарач». Виноградарство и виноделие. - 2018. - № 1. $-C .7-9$.

Studennikova N.L., Kotolovec' Z.V. Klon vinograda sorta Kokur belyj s osypaniem cuetkov $i$ chastichnym gorosheniem jagod [A clone of 'Kokur belyi' cultivar with blossom fall and partial formation of small berries] // Magarach" Vinogradarstvo $i$ vinodelie ["Magarach" Viticulture and winemaking]. 2018. № 1. p. 7-9. (in Russian)

5. Левинский, А. И. Филлоксероустойчивые подвои винограда в запад- 
ных предгорьях Крыма // А.И. Левинский, Ю.А.Белинский, Е.В. Ботнарь // Садоводство и виноградарство. - 1989. - № 12. - С. 33-35.

Levinskij A.I., Belinskii Ju.A., Botnar' E.V. Fillokseroustojchivye podvoi vinograda $v$ zapadnyb predgor'jab Kryma [Phylloxera-resistant grape rootstocks in the western foothills of the Crimea] // Sadovodstvo i vinogradarstvo [Gardening and Viticulture]. 1989. № 12. pp. 33-35. (in Russian)

6. Becker, A. Newly Bred Varieties of Phylloxera Tolerant Rootstocks / A. Becker, J. Herrmann // Workshop. Geisenyeim Research Centre Germany. -2001. - P. 16.

7. Crecu, V. Introducerca in sortiment a soiului de portaltoi Ruggeri $140 \mathrm{~N}$. Crecu //Veget. Hortic. - 1981. - № 10. - P. 19-24.

8. Lafotaine, M. Rootstock efeect on guality / M. Lafotaine, H. Schultz //Workshop. Geisenheim Research Ctntre. Germany. - 2001. - 19 p.

9. Лилов, Д. Производство на лозов посадъчен материал / Д. Лилов, И. Димитров. - София: Земиздат, 1970. - 208 с.

Lilov, D. Proizvodstvo na lozov posadüchen material [Production of vine planting material] / D. Lilov, I. Dimitrov. - Sofiya: Zemizdat, 1970. - 208 s.Lilov, E / D. Lilov, I. Dimitrov. - Sofia: Zemizdat, 1970. - 208 p.

10. Pauget, R. Rivista Viticoltura Enologia / R. Pauget. - 1984. - 37. - 133 p.

11.Самборская, А. К. Выбор подвоев для технических сортов винограда /А.К. Самборская, Н.Н. Пилипенко, П.П. Самборский // Садоводство, виноградарство и виноделие Молдавии. - 1978. - № 2. - С. 26-28.

Samborskaja A.K., Pilipenko N.N., Samborskij P.P. Vybor podvoev dlja tehnicheskih sortov vinograda [Selection of rootstocks for technical grape varieties] // Sadovodstvo, vinogradarstvo $i$ vinodelie Moldavii [Gardening, Viticulture and Winemaking of Moldova]. 1978. № 2. pp. 26-28. (in Russian)

12. Кривошей, И.А. Потенциальная плодоносность сортов винограда Кокур белый и Шабаш на различных элементах рельесра / И.А. Кривошей // «Магарач». Виноградарство и виноделие. - 2018. - № 1. - C.7-9.

Krivoshej I.A. Potencial'naja plodonosnost' sortov vinograda Kokur belyj $i$ Shabash na razlichnyb jelementab rel'efa [Potential fruiting capacity of 'Kokur belyi' and 'Shabash' grapevine cultivars on various terrain elements] //Sel'skobozjajstvennye nauki: Sb.nauch. tr. - Simferopol': KGAU. [Agricultural Sciences: Coll. tr.] ]Simferopol: KGAU. 2000. Vol. №66. pp. 217-220. (in Russian)

13. Грамотенко, П. М. Гибриды винограда донского сорта Пухляковский / П.М. Грамотенко // Авторефрерат дисс. канд. биологических наук. Ростов-на-Дону, 1955. - 16 с.

Gramotenko P.M. Gibridy vinograda donskogo sorta Publjakovskij [Don grape hybrids Puhlyakovsky]//Avtoreferat diss, kand. biologicheskih nauk. - Rostov-na-Donu [Abstract of Diss. Cand. biological sciences]. Rostov-on-Don. 1955. 16 p. (in Russian)

14. Лазаревский, М. А. Изучение сортов винограда / М.А. Лазаревский. - Ростов- на- Дону: Изд. Ростовского ун-та, 1963. - 152 с.

Lazarevskij M.A. Izuchenie sortov vinograda. [The study of grapes]. Rostov-on-Don: ed. Rostov un-that. 1963. 152 p. (in Russian)

15. Простосердов, Н. Н. Основы виноделия / Н.Н. Простосердов. - М.: Пищепромиздат, 1955. - С. 16-31.

Prostoserdov N.N. Osnovy vinodelija [Basics of winemaking]. Moscow. 1955. pp. 16-31. (in Russian)

16. Амирджанов, А. Г. Новые подходы к оценке продуктивности сортов винограда / А.Г. Амирджанов // Виноградарство и виноделие СССР. Ялта. - 1989. - Вып. 2. - С. 61-67.

Amirdzhanov A.G. Novye podhody k ocenke produktivnosti sortov vinograda [New approaches to assessing the productivity of grape varieties] // Vinogradarstvo i vinodelie SSSR [Viticulture and Winemaking of the USSR]. Yalta. 1989. Vol. 2. pp. 61-67. (in Russian)

17. Ермолин, Д. В. Физико-химические показатели виноматериалов для мускатных игристьх вин / Д.В. Ермолин, Г.В. Ермолина, Д.С. Задорожная // Известия сельскохозяйственной науки Тавриды. - 2015. № 4 (167). - C. 78-81.

Ermolin D.V., Ermolina G.V., Zadorozhnaja D.S. Fiziko-bimicheskie pokazateli vinomaterialov dlja muskatnyb igristyb vin [Physical and chemical indicators of wine materials for muscat sparkling wines] //Izvestija sel'skobozjajstvennojnauki Tavridy [Proceedings of Agricultural Science Tavrida]. 2015. № 4 (167). pp. 78-81. (in Russian) 